\title{
Evaluation of high cut Dega osteotomy for management of developmental hip dysplasia in children
}

Hesham Hamed Refae ${ }^{\mathrm{a}}$,Elsayed Abdel-hamid Ahmed ${ }^{\mathrm{b}}$,Mohamed Tageldeen Elemary ${ }^{c}$, Emad Hamdy Morsy Ahmed ${ }^{b, *}$

${ }^{a}$ Department of Orthopaedic Surgery, Faculty of Medicine, Aswan University, Aswan, Egypt.

${ }^{b}$ Department of Orthopaedic Surgery, Faculty of Medicine, South Valley University, Qena, Egypt.

${ }^{c}$ Department of Orthopaedic Surgery, Faculty of Medicine, Cairo University, Cairo, Egypt.

Abstract
Background: Developmental dysplasia of the hip (DDH) is a spectrum of pathologic
changes affect the developing hip. Dega acetabuloplasty is considered one of the
favorable reshaping procedures and it is most valuable in severe dysplasia without need
for internal fixation. High cut Dega osteotomy is a modification for the typical Dega
procedure by making the osteotomy at a higher level close to salter osteotomy. So, it
facilitates the basic Dega procedure and produces a Salter-like effect.
Objectives: to evaluate theclinical and radiological outcomes of the management of
DDH by high cut Dega osteotomy.
Patients and Methods: This prospective study included 20 patients with 25 involved
hips who presented with DDH between walking age and under 3 years of age, High cut
Dega osteotomy were conducted in 13 patients in Abo-Elreesh-Hospital and 7 patients in
Qena University Hospital between March 2017 and March 2021 .
Clinical status was assessed using modified McKay criteria; radiological evaluations
were assessed using the modified Severinclassification, the mean acetabular index
(AI),and centeredge (CE) angles.
Results: The final clinical resultswere satisfactory in 24 hips (96\%) and unsatisfactory in
one (4\%), there was a statistically significant improvement in acetabular index and center
edge at the final follow up.
Conclusions: Our modified technique gives similar results to the Dega procedure but
avoid iatrogenic insults to the acetabulum and rare early closure of the triradiated
cartilage, which might lead to acetabular dysplasia.
Keywords: DDH, High cut Dega, pelvic osteotomy

Copyright: () Refae et al. (2021) Immediate open access to its content on the principle that making research freely available to the public supports a greater global exchange of knowledge. Users have the right to Read, download, copy, distribute, print or share link to the full texts under a Creative Commons BY-NC-SA 4.0 International License. 


\section{Introduction}

Developmental dysplasia of the hip refers to a spectrum of pathologic changes in the developing hip, ranging from acetabular dysplasia tosubluxation of the hip or dislocation.(Lieberman, 2009)

DDH is the most common childhood hip disorder. 10 in 1,000 children $(1 \%)$ are born with hip subluxation or dysplasia. One in 1,000 children $(0.1 \%)$ are born with a dislocatable hip. $80 \%$ of affected children are females. The left side is more commonly affected (60\%).(Vitale and Skaggs, 2001; Lieberman, 2009)

In untreated cases over 18 months operative management is usually suggested. Surgical treatment of DDH includes open reduction, capsulorrhaphy plus or minus a suitable type of pelvic osteotomy and or femoral osteotomy.(Grudziak and Ward, 2001; Karlenet al., 2009; Lieberman, 2009)

Selection of the pelvic osteotomy is based on the degree of the dysplasia and the age of the child. Regarding types of pelvic osteotomies there are reorientation procedures and reshaping procedures.(Campbellet al., 2008;

\section{López et al., 2008)}

The Salter osteotomy is a single osteotomy at the inferior gluteal line. It is a reorientation osteotomy, lead to increase the anterior and lateral coverage, but reduce the posterior coverage. A drawback of Salter technique is need for another surgery to remove hardware.(Pekmezci and Yazici, 2007)

Dega osteotomy is considered one of the reshaping pelvic osteotomies. It is supraacetabular semicircular osteotomy in which semicircular cut through the lateral cortex of the ilium directed towards the medial cortex of the ilium just above the triradiate cartilage.(López et al., 2008; Karlen et al., 2009)

The high osteotomy cut is a modification of Dega procedure was found to be effective for improving radiographicand clinical results but includes less complications for walking DDH patients, as iatrogenic damage to triradiate cartilage and further acetabular dysplasia.(Ming-Huaet al., 2016) The aim of our study is to evaluate clinical and radiological outcomes of the management of DDH by high cut Dega osteotomy.

\section{Patients and methods}

This prospective study included 20 patients with 25 involved hips who presented with DDH between walking age and under 3 years of age, the surgeries were conducted in 13 patients in Abo-Elreesh-Hospital and 7 patients in Qena University Hospital between March 2017 and March 2021. an institutional ethical committee approval was taken. Informed Consent was taken from all parents.

Patients were included if they were below 3 years of age and who received no operative treatment before. Patients with teratologic, postseptic, syndromatic, or recurrent dislocation were not included in the study.

The study included 17 girls and 3 boys, mean age $1.77 \pm 0.557$ years (range $1-3$ years). 5 patients had bilateral dislocation, whereas 10 had left-sided and 5 had right-sided dislocation. 


\section{Treatment protocol}

was designed for the management of these cases in the form of open reduction, capsulorrhaphy accompanied with high Dega pelvic osteotomy with or without femoral osteotomy when needed.

\section{Operative technique}

Following open reduction, high cut Dega osteotomy was performed, starting above the anterior inferior iliac spine, propagating toward the greater sciatic notch as a greenstick, leaving the posterior portion of the iliac cortex intact so creating ahinge at the remaining incomplete fractured posterior ilium and sciatic notch.

After that, a bone graft is inserted in the osteotomy gap. (Figure 1)

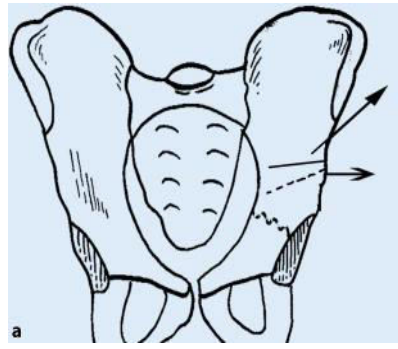

Figure 1: The high cutDega osteotomy. A: anteroposterior view; B: lateral aspect of the ilium.(Ming-Huaet al., 2016)

\section{Postoperative immobilization}

A plaster or a fiberglass hip spica cast is made,

\begin{tabular}{|l|l|}
\hline \multirow{2}{*}{ Excellent } & $\begin{array}{l}\text { Stable, painless hip, no limp, } \\
\text { negative Trendelenburg sign, } \\
\text { full range of motion }\end{array}$ \\
\hline Good & $\begin{array}{l}\text { Stable, painless hip, slight limp, } \\
\text { negative Trendelenburg sign, } \\
\text { slight loss of hip movement }\end{array}$ \\
\hline Fair & $\begin{array}{l}\text { Stable, painless hip, limp, } \\
\text { positive Trendelenburg sign, } \\
\text { moderate stiffness }\end{array}$ \\
\hline Poor & $\begin{array}{l}\text { Unstable and/or painful hip; } \\
\text { positive Trendelenburg sign }\end{array}$ \\
\hline
\end{tabular}

\section{Evaluation of the results}

Patients were followed up clinically and radiologically using modified McKay criteria and Severin classification, respectively.

\section{Statistical analysis :}

Data were verified, coded by the researcher, and analysed using IBM-SPSS v. 21.0.0 (SPSS Inc., Chicago, IL, USA). Continuous variables were expressed as mean \pm standard deviation and analysed with the Student $t$ test. Categorical ones were expressed as percent value and analysed with Fischer test or Chisquare test, where appropriate. $\mathrm{P}<0.05$ were considered statistically significant.

(Table 1):Clinical evaluation byModified McKay's criteria.(Badgley, 1943)

with the hip in slight abduction, flexion, and neutral rotation. 
(Table 2): Radiographic grading of results using Severin's radiological criteria.(Badgley, 1943)

\section{Results}

\begin{tabular}{|c|c|}
\hline Grade 1 & $\begin{array}{l}\text { - Normal hip } \\
\text { - } \mathrm{CE} \text { angle }>15 \text { degrees in children } \\
\text { - } \mathrm{CE} \text { angle }>25 \text { degrees in adults }\end{array}$ \\
\hline Grade 2 & $\begin{array}{l}\text { - Mild deformity of head or neck } \\
\text { - Hip deeply and concentrically reduced. } \\
\text { - CE angle as grade } 1\end{array}$ \\
\hline & $\bullet$ \\
\hline Grade 3 & $\begin{array}{l}\text { - Dysplastic hips without subluxation } \\
\text { - } \mathrm{CE} \text { angle }<15 \text { degrees in children } \\
\text { - } \mathrm{CE} \text { angle }<20 \text { degrees in adults }\end{array}$ \\
\hline Grade 4 & - Subluxation \\
\hline Grade 5 & $\begin{array}{l}\text { - Head articulating with a false acetabulum in the } \\
\text { upper part of the original acetabulum }\end{array}$ \\
\hline Grade 6 & - Redislocation \\
\hline
\end{tabular}

25 hips in 20 patients were included in this study. Table 3 demonstrates patients' demographic characteristics in terms of age, gender, bilaterality and follow up duration. Preoperatively, according to Tonnis classification, 13 hips were grade IV, 10 hips were grade III, and 2 hips were grade

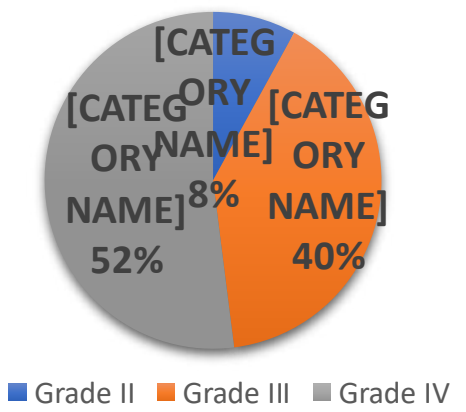

Figure 2 : Tonnis classification

\section{II(Figure 2).}


(Table 3): Demographic Data

\begin{tabular}{lcccc}
\hline & N & \% & Mean \pm SD & Range \\
\hline Age, $\mathbf{y}$ & - & - & $1.77 \pm 0.557$ & $1-3$ \\
\hline $\begin{array}{l}\text { Gender } \\
\quad \text { Female }\end{array}$ & 17 & 85 & - & - \\
$\quad$ Male & 3 & 15 & & - \\
\hline $\begin{array}{l}\text { Injured side } \\
\quad \text { Right }\end{array}$ & 5 & 25 & - & $18-48$ \\
$\quad$ Left & 10 & 50 & & \\
$\quad$ Bilateral & 5 & 25 & $33.3 \pm 10.04$ & \\
Follow up, months & - & - & & \\
\hline 20 patients, 25 limbs & & &
\end{tabular}

As shown in Table 4, all 25 hips underwent high Dega osteotomy. Two

hips (8\%) required femoral shortening. Average operative time was 98.25 min (SD; 12.9), and ranged from 80 to $125 \mathrm{~min}$. Average blood loss was $100.5 \mathrm{ml}$ (SD; 13.46), and ranged from 85 to 130ml.patients were followed up both clinically and radiologically fora period ranged from 18 to 48 months. At the final follow up, final clinical and radiological results were evaluated.

\section{Clinical results (Table 5)}

The finalresult was excellent in 22 hips $(88 \%)$, good in two $(8 \%)$, fair in one (4\%), and no cases had poor results. Therefore, satisfactory results were obtained in 24 hips (96\%) and unsatisfactory in one (4\%) (Figure 3).
(Table 4): Operative Data

\begin{tabular}{|c|c|c|c|c|}
\hline & $\mathbf{N}$ & $\%$ & $\begin{array}{c}\text { Mean } \pm \\
\text { SD }\end{array}$ & Range \\
\hline $\begin{array}{l}\text { High Dega } \\
\text { Osteotomy }\end{array}$ & 25 & 100 & - & - \\
\hline $\begin{array}{l}\text { Femoral } \\
\text { shortening }\end{array}$ & 2 & 8 & - & - \\
\hline $\begin{array}{l}\text { Operative } \\
\text { time, min }\end{array}$ & - & - & $\begin{array}{c}98.25 \pm \\
12.9\end{array}$ & $80-125$ \\
\hline $\begin{array}{l}\text { Blood Loss, } \\
\text { ml }\end{array}$ & - & - & $\begin{array}{c}100.5 \pm \\
13.46\end{array}$ & $85-130$ \\
\hline $\begin{array}{l}20 \text { patients, } \\
25 \text { limbs }\end{array}$ & & & & \\
\hline
\end{tabular}

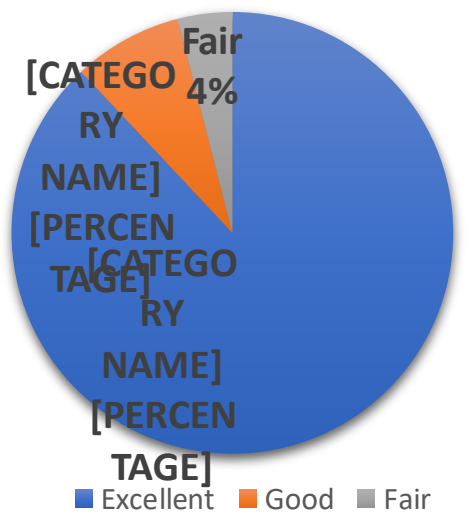

Figure (3): McKay Criteria 
Refae et al (2021)

SVU-IJMS, 4(2): 246- 256

(Table 5): Clinical Results

\begin{tabular}{lcc}
\hline & N & $\%$ \\
\hline Stability & 25 & 100 \\
$\quad$ Stable & 0 & 0 \\
$\quad$ Unstable & 25 & 100 \\
\hline Pain & 0 & 0 \\
$\quad$ No & & \\
$\quad$ Yes & 22 & 88 \\
\hline ROM & 2 & 8 \\
$\quad$ No limitation & 1 & 4 \\
$\quad$ Mild limitation & & \\
$\quad$ Moderate limitation & 22 & 88 \\
\hline Limping & 3 & 12 \\
$\quad$ No & & \\
$\quad$ Yes & 24 & 96 \\
\hline Trendelenburg & 1 & 4 \\
$\quad$ No & & \\
$\quad$ Yes & 22 & 88 \\
\hline McKay Criteria & 3 & 4 \\
$\quad$ Excellent & 1 & 0 \\
Good & 0 & \\
Fair & & \\
Poor & & \\
\hline 20 patients, 25 limbs & & \\
\hline
\end{tabular}

(Table 6): Radiological results

\begin{tabular}{lcc}
\hline & N & \% \\
\hline Shenton Line & & \\
Intact & 24 & 96 \\
Broken & 1 & 4 \\
\hline Severin Classification & & \\
Class 1 & 17 & 68 \\
Class 2 & 7 & 28 \\
Class 3 & 1 & 4 \\
Class 4 & 0 & 0 \\
\hline 20 patients, 25 limbs & &
\end{tabular}


(Table 7): Comparison of Radiological parameters Preoperatively, Postoperatively and Last Follow Up (20 patients, 25 limbs)

\begin{tabular}{lcccc}
\hline & Preoperative & Postoperative & Last Follow up & P value \\
\hline AI, deg & $35.76 \pm 4.9$ & $25.84 \pm 3.93$ & $21.52 \pm 2.85$ & $.024^{\mathrm{a}}$ \\
\hline CEA, deg & - & $27.04 \pm 8.58$ & $31.88 \pm 6.8$ & $.015^{\mathrm{b}}$ \\
\hline${ }^{\mathrm{a}}$ Repeated measure ANOVA, ${ }^{\mathrm{b}}$ Wilcoxon test & & \\
\hline
\end{tabular}

\section{Radiological results (Tables 6,7)}

The radiological result was evaluated according to Severin's radiological criteria (Figure 4).It was class1 (excellent) in 17 hips $(68 \%)$, class 2 (good) in $7(28 \%)$, and class 3 (fair) in one hip (4\%). Therefore, satisfactory results were obtained in 24 hips $(96 \%)$ and unsatisfactory in one $(4 \%)$. In addition, postoperative imaging showed 24 hips with intact Shenton line, while only one hip had a broken Shenton line.

The preoperative acetabular indices ranged from $24^{\circ}$ to $49^{\circ}$ degree with mean of $35.76^{\circ}$.
The acetabular index was improved in all hips at last evaluation. The postoperative acetabular indices on the last examination ranged from $15^{\circ}$ to $25^{\circ}$ with a mean of $21.52^{\circ}$.

There was statistically significant improvement after surgery $(\boldsymbol{P}=.000)$.

Preoperatively, the CE angle of Weiberg was negative in all hips. There was a statistically significant improvement in center edge angle from a postoperative mean of $27.04^{\circ} \pm 8.58^{\circ}$ (range from $15^{\circ}$ to $50^{\circ}$ ) to a mean of $31.88^{\circ} \pm 6.8^{\circ}$ (range from $22^{\circ}$ to

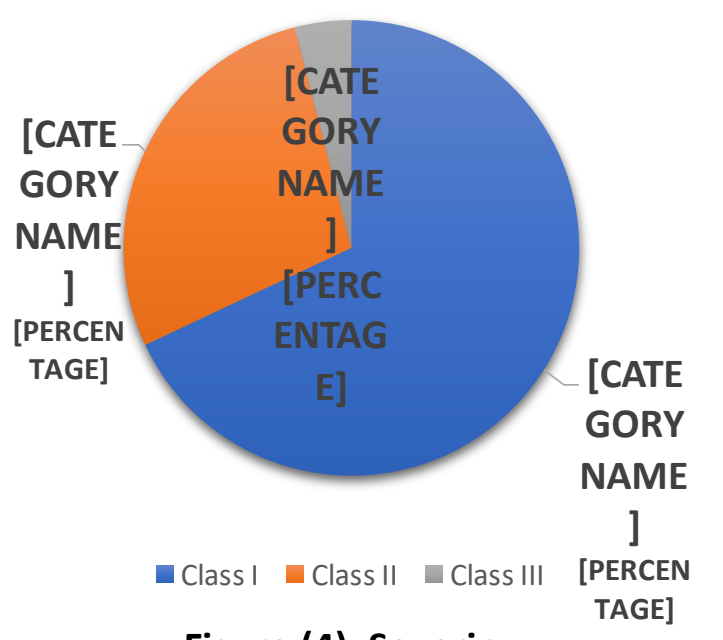

Figure (4): Severin classification

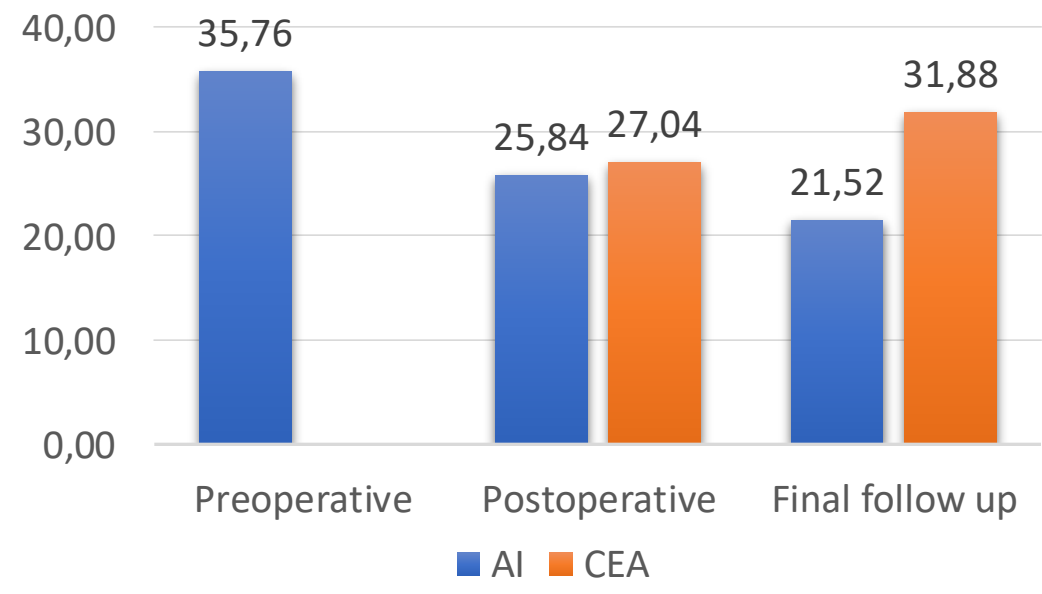

Figure (5): Comparison between the radiographic parameters pre-operatively, postoperatively and at last follow up 
$\left.45^{\circ}\right)$ at the final follow up $(\boldsymbol{P}=.000)$

(Figure 5).

Relation between the final radiological and clinical results (Table 8)

There were 17 hips (68\%) with Severin's class I; all of them had satisfactory clinical results (15 were excellent and 2 were good). Seven hips (28\%) with Severin's grade II; six had satisfactory clinical results (all were excellent) and one hips had unsatisfactory outcomes (fair). one (4\%) with Severin's class III had satisfactory clinical result.

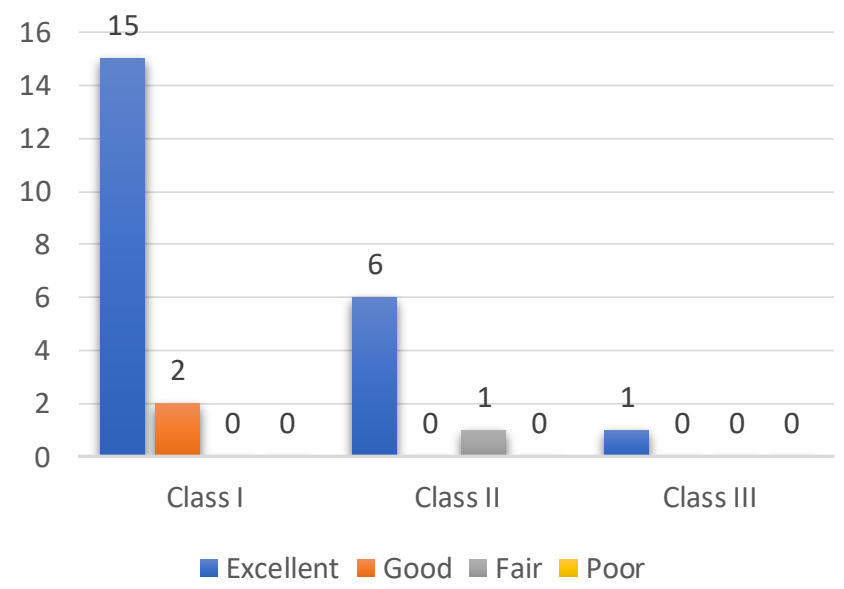

Figure (6): Relation Between Radiological and Clinical Outcomes

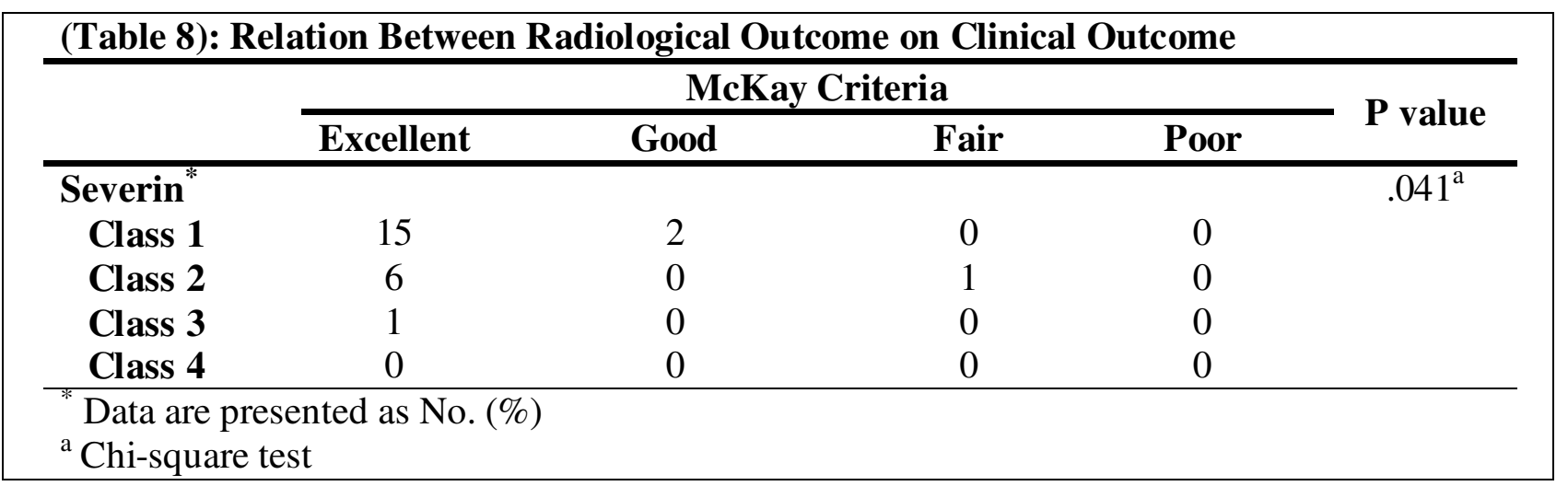

None were Severin grade IV (Figure 6).

There was a statistically significant relation between final radiological and clinical results. $(\boldsymbol{P}=.041)$.

\section{Postoperative complications (Table 9)}

Twenty hips $(80 \%)$ had no postoperative complications. Two cases of subluxation

(Table 9): Postoperative complications

\begin{tabular}{lcc}
\hline & N & \% \\
\hline None & 20 & 80 \\
\hline Subluxation & 2 & 8 \\
\hline Re-dislocation & 1 & 4 \\
\hline Stiffness & 1 & 4 \\
\hline Ulcer & 1 & 4 \\
\hline 20 patients, 25 limbs & &
\end{tabular}
were reported, one case of recurrent dislocation, one case developed hip stiffness and one case had skin ulcer. 


\section{Discussion}

In our study we introduce this modification on dega osteotomy in a simple manner by making the osteotomy at a higher level close to salter osteotomy. So, it simplified the initial Dega procedure and avoid iatrogenic insult to acetabulum and triradiate cartilage.

Our hypothesis suggests that our modified technique will give similar results to the Dega procedure but avoid iatrogenic insults to the acetabulum and rare premature closure of the triradiated cartilage, which might also lead to residual acetabular dysplasia via cut away from the open triradiate cartilage and avoided the inconvenience of creating fragment instability or requirement for internal fixation as in salter osteotomy.

The study of Ming-Hua et al was a retrospective study of the results of $\mathrm{Dr} \mathrm{Xu}$ Rui-Jiang's operative experience with the high Dega osteotomy procedure for the treatment of children below 6 years of age between September 2000 and September 2010. data from this study demonstrated that the application of a high osteotomy cut Dega procedure for children below 6 years old was effective treatment in improving clinical and radiographic outcomes in hip rehabilitation. And avoid complication that would occur with initial Dega osteotomy.(Ming-Hua et al., 2016)
In our study, 20 patients (25 hips) with developmental dislocation of the hip had different combinations of open reduction and high cut Dega pelvic osteotomy \pm femoral osteotomy when needed. The age ranged from 1 to 3 years. 24 hips (22 excellent and 2 good) (96\%) had satisfactory clinical result and unsatisfactory results in one $(4 \%)$.

The AI in our study was used as one of the references of the acetabular remodelling after high cut Dega osteotomy. It improved from mean of $35.76^{\circ}$ (range $24^{\circ}$ to $49^{\circ}$ ) preoperatively to mean of $21.52^{\circ}$ (range $15^{\circ}$ to $25^{\circ}$ ) at final follow up. This shows the high efficacy of high cut Dega pelvic osteotomy in restoration of AI close to normal values.

The $\mathrm{CE}$ angle in our study improved from negative in all the patients preoperatively to mean of $31.88^{\circ}$ (range $22^{\circ}$ to $45^{\circ}$ ) at the final follow up.

There were 17 hips (68\%) with Severin's class I; all of them had satisfactory clinical results (15 were excellent and 2 were good). Seven hips (28\%) with Severin's grade II; six had satisfactory clinical results (all were excellent) and one hips had unsatisfactory outcomes (fair). one (4\%) with Severin's class III had satisfactory clinical result. None were Severin grade IV. There was a 
statistically significant relation between final radiological and clinical results.

The study of Ming-Huaon 2016 involved A 162 patients (191 hips) retrospectively were included in this study: 28 male and 134 fem0ale, 29 bilateral hips and 133 unilateral hips (right 47, left 86), 7 residual dysplastic, 32 subluxated and 152 dislocated hips respectively at the time of the index procedures. The average age was 3.6 years (range 1.5 to 6.0 ), mean duration of follow up 11.3 years (range 5.0 to 16.9). high cut Dega acetabuloplasty were done for all the patients. The results were $77 \%$ excellent, $15.7 \%$ good, regarding the clinical fineness ratio (favorable and good) as 92.7\%; and radiological evaluations $74.3 \%$ (142 hips) as excellent, $16.8 \%$ (32 hips) as good, regarding the radiological fineness ratio (favorable and good) to be $91.1 \%$.(Ming-

\section{Hua et al., 2016)}

In the previous study the high cut dega osteotomy was not intended by the surgeon as it is discovered accidently While discussion ofpostoperative radiographic results of Dega procedureas described by Grudziak and Ward in their institution.(Ming-Hua et al., 2016)

Nakamura reported the results of treatment of 11 hips with congenital dislocation treated by femoral varusderotation and shortening concomitant with open reduction.
Age was averaged 2 years and 1 month;period of follow up averaged 15 years and 7 months; and age at lastfollow up averaged 17 years and 8 months. At the last follow up eight $(75 \%)$ and five $(45 \%)$ of hips had good clinical and radiographic results respectively. They added that the six hips that had poor radiological results were complicated by mild femoral head a vascular necrosis, five of which had had abnormal ossific nuclei pre-operatively. (Arslan et al., 2007).

In our study there was nofemoral head avascular necrosis at the time of last follow up.

Zionts and MacEwenhave major AVN in two $(5 \%)$ of their patients after 5 to 20 years follow up.(Zionts and MacEwen, 1986)

\section{Conclusion}

Acetabular index, $\mathrm{CE}$ angle, were found to be the most important predictive factors to be measured pre and postoperatively.

High cut Dega osteotomy is sufficient treatment in improving clinical and radiographic results in DDH. It could be used as a reconstructive method for treatment of DDH patients, it is stable with no need for fixation hence no need for another operation to remove the wires.the remaining incomplete fractured posterior ilium and sciatic notch act as a hing, with rotation of the open triradiate cartilage and 
unrestricted symphysis pubis. so, in high cut

Dega osteotomy the risk of damage of the triradiate cartilage is much less than in typical dega osteotomy.

\section{References}

Arslan H, Kapukaya A, Ibrahim Bekler H, Necmioğlu S. (2007).Is varus osteotomy necessary in one-stage treatment of developmental dislocation of the hip in older children, Journal of children's orthopaedics, 1(5): 291-297.

Badgley CE. (1943). Correlation of clinical and anatomical facts leading to a conception of the etiology of congenital hip dysplasias, JBJS, 25(3): 503-523.

$\begin{array}{llr}\text { Campbell WC, Canale } & \text { ST, Beaty } \\ \text { JH.(2008). } & \text { Campbell's } & \text { operative } \\ \text { orthopaedics. } & \text { Philadelphia, } & \text { PA: } \\ \text { Mosby/Elsevier. } & & \end{array}$

Grudziak JS, Ward WT.(2001).Dega osteotomy for the treatment of congenital dysplasia of the hip, JBJS, 83(6): 845-854.

Karlen JW, Skaggs DL, Ramachandran M, Kay RM. (2009). The Dega osteotomy: a versatile osteotomy in the treatment of developmental and neuromuscular hip pathology, Journal of Pediatric Orthopaedics, 29(7): 676-682.

Lieberman JR. (2009). AAOS comprehensive orthopaedic review american academy of orthopaedic surgeons, Rosemont, Illinois, : 1101-1109.

López E, Carillo H, Gutiérrez M. (2008). Dega versus Salter osteotomy for the treatment of developmental dysplasia of the hip, Journal of Pediatric Orthopaedics B, 17(5): 213-221.

Ming-Hua D, Rui-Jiang X, Wen-Chao L. (2016). The high osteotomy cut of Dega procedure for developmental dysplasia of the hip in children under 6 years of age, Der Orthopäde, 45(12): 1050-1057.

Pekmezci M, Yazici M. (2007). Salter osteotomy: an overview, Acta Orthop Traumatol Turc, 41(Suppl 1): 37-46.
Vitale MG, Skaggs DL. (2001). Developmental dysplasia of the hip from six months to four years of age, JAAOS-Journal of the American Academy of Orthopaedic Surgeons, 9(6): 401-411.

Zionts LE, MacEwen GD.(1986). Treatment of congenital dislocation of the hip in children between the ages of one and three years, The Journal of bone and joint surgery. American volume, 68(6): 829-846. 